\title{
Preface: Pheromone-Mediation of Female Reproduction and Reproductive Dominance in Social Species
}

\author{
Etya Amsalem ${ }^{1}$ (D) Abraham Hefetz ${ }^{2,3}$
}

Published online: 16 July 2018

(C) Springer Science+Business Media, LLC, part of Springer Nature 2018

Reproductive skew, a common feature in social animals, is an evolutionary enigma requiring both ultimate and proximate explanations. At the ultimate level, the question is whether reproductive subordination is coercive or self-restrained, i.e., whether the dominant reproductive forcefully inhibits the subordinate's reproduction, or the subordinate actually expresses reproductive restraint directed by inclusive fitness considerations (Hamilton 1972; Keller and Nonacs 1993). At the proximate level, the question is not only what are the mechanisms regulating reproductive skew, but also whether they are shared across species, either by being conservatively shared among phylogenetically-related social species or via convergent or parallel evolution with different species adopting similar strategies to regulate reproduction.

Many signals, especially in insects, are hypothesized to have evolved from non-communicative cues that are a byproduct of physiological processes (Bradbury and Vehrencamp 2001; Stökl and Steiger 2017; Wyatt 2014a). However, we have a limited understanding of the signals and mechanisms regulating reproduction, and in many cases they appear diverse and involve different modalities of communication, affecting both the behavior and the physiology of the recipients (Schulz 2004; Symonds and Elgar 2008). What

Etya Amsalem eua6@psu.edu

$\triangle$ Abraham Hefetz hefetz@post.tau.ac.il

1 Department of Entomology, Center for Chemical Ecology, Center for Pollinator Research, Huck Institutes of the Life Sciences, Pennsylvania State University, University Park, State College, PA 16802, USA

2 School of Zoology, George S. Wise Faculty of Life Sciences, Tel Aviv University, Tel Aviv, Israel

3 School of Marine Sciences, Ruppin Academic Center, Emek Hefer, Israel kinds of signals are used to regulate female reproduction? Do they act coercively or informatively? How conserved are these signals and the physiological pathways they target in females? How do they evolve? And to what extent are they rooted in signals or cues regulating reproduction in non-social species? All of these are longstanding questions in the study of social evolution.

One striking example of pheromones that evolved from non-communicative cues that are a by-product of physiological processes is that of the urinary composition in mammals. Female house mice produce volatile compounds in their urine in order to regulate the reproduction of other females as well as to communicate their reproductive status to other females and males (Champlin 1971; Drickamer 1974; Massey and Vandenbergh 1980; McIntosh and Drickamer 1977). Specifically, 2,5-dimethylpyrazine is the key component in the female urine and it has been shown to lengthen the oestrus cycle of female house mice kept in groups as a means to reduce competition ("Lee-Boot effect", Van Der Lee and Boot 1955), and to cause delayed puberty in both male and female mice (Jemiolo and Novotny 1993; Jemiolo and Novotny 1994). Urine is a highly efficient vehicle for the transmission of signals, and an especially good system by which to transmit honest signals, since several of the urine compounds are derivatives of major classes of steroid hormones (Nodari et al. 2008), suggesting that the signaling system is a by-product of the females' physiology. Furthermore, the effect can be fully achieved whether using live females or only with their urine (Drickamer 1974; McIntosh and Drickamer 1977), suggesting that the signal is coercive. Male urine constituents are also known to regulate female physiology (Coombes et al. 2018), and in turn, females relate to male urine when choosing mate (Green et al. 2015). However, the house mouse system is one of the few systems in which our understanding of the reproductive signaling system is comprehensive, and similar investigations, particularly in social insect species, are warranted. 
Studies seeking to explain reproductive skew, however, need to be carried out with great caution and to follow strict guidelines, since the explanations to some of these mechanistic and evolutionary questions can be easily confounded. For example, much work has been conducted on the role of cuticular hydrocarbons (CHCs) in regulating behavior in insects. These arrays of typically long-chained linear and branched, saturated and unsaturated, hydrocarbons are highly abundant on the insect epicuticle and highly informative. Variation in CHC composition can be achieved genetically as well as environmentally through food, gut microbes, or nest-site material (d'Ettorre and Lenoir 2010), which provide information specific to species, sex, age, health, mating status, social hierarchies, kin, nestmates, caste, and, particularly pertinent to this special issue, female reproductive status (Howard and Blomquist 2005; Kather and Martin 2015; Smith and Liebig 2017). However, the ubiquitous occurrence of hydrocarbons, coupled with their easy detection and synthesis through common methodologies, may bias our conclusion regarding their importance in regulating reproductive decisions, compared to the more elaborate chemical signals. Such a bias may further lead to conclusions such as hydrocarbons may act to coercively inhibit worker reproduction or that their role in regulating reproduction in social insects is conserved across taxa (Oi et al. 2016; Van Oystaeyen 2014; but see Amsalem et al. 2015; Kather and Martin 2015; Nunes et al. 2017 for different conclusions). It is not inconceivable that, similar to the highly chemically-diverse alarm or trail pheromones of social insects, pheromone-regulating reproduction are diverse rather than conserved.

In this special issue, we explore both the ultimate and proximate aspects of reproductive dominance, focusing on behavioral and chemical signals that are mediators of many social interactions, including the reproductive division of labor (Wilson and Holldobler 2005; Wyatt 2014b). While behavioral means for reproductive dominance are common across all social species (Holldobler and Wilson 1990; Michener 1974), chemical communication, although common to many systems (Hoffmann et al. 2006), is typically considered to be an advanced feature of social behavior, marking the transition from the use of aggression to establish dominance hierarchies in small groups of cooperative females, to the use of pheromones to regulate task allocation and reproduction in the sterile worker caste (Kocher and Grozinger 2011; Le Conte and Hefetz 2008). Studying these chemicals, their structures and mode of action, the physiological pathways they target, and their regulation in multiple social and non-social systems across different taxa, can shed light on and identify the shared motifs, mechanisms and evolutionary pathways of these signals, as well as generate predictions regarding as yet undefined pheromones. We review cases at all levels of sociality, emphasizing the transition from solitary to social living in animals, in an attempt to delineate possible common and conserved evolutionary pathways as well as the mechanisms involved, pertaining in particular to the nature, structures, and origin of the chemical signals.

The chapters included in this issue have been designed to provide an in-depth overview of these regulatory mechanisms in solitary species (Billeter and Wolfner 2018; Coombes et al. 2018), Hymenopteran insect species (Dani and Turillazzi 2018; Steitz et al. 2018; Villalta et al. 2018) and nonhymenopteran insect species (Abbot et al. 2018; Korb 2018; Steiger and Stökl 2018) as well as in parasite species that mimic the mechanisms used by their host (Lhomme and Hines 2018). This cross-disciplinary examination of the literature identifies the key principles in understanding the ultimate and proximate mechanisms regulating reproduction. For example, the study by Billeter and Wolfner (2018) highlights the importance of understanding sexual conflicts and the ecological conditions when examining the role of pheromones. The role of hydrocarbons as honest signals of fertility has been highlighted in several of the species investigated (Dani and Turillazzi 2018; Korb 2018; Lhomme and Hines 2018; Villalta et al. 2018). Other social systems provide a unique opportunity to study the evolution of signals and social behavior: sub-social species like burying beetles that present a primitive form of sociality (Steiger and Stökl 2018), and species in which sociality has evolved (and reversed) multiple times, as in halictid bees (Steitz et al. 2018), provide excellent model systems by which to understand the transition from the use of behavioral to chemical means to regulate reproduction and social behavior, and to identify shifts in the transition from the functional to the communicative role of pheromones. Aphids offer a glance into the relationship between social behavior and the chemical ecology of plant-insect interactions, providing an opportunity to examine the bottom-up and top-down effects of these interactions on the evolution of social traits in herbivorous insect species (Abbot et al. 2018). Finally, termites are the only non-hymenopteran species in which both simple and advanced eusociality has evolved, providing an excellent model by which to examine the evolution of pheromones in non-haplo-diploid systems (Korb 2018). These articles together provide an exciting overview of the diverse cues and signals that regulate female reproduction, the role that pheromones play in 'hacking' wellconserved sites that regulate reproduction, and the evolution of complex social systems.

\section{References}

Abbot P, Tooker J, Lawson SP (2018) Chemical ecology and sociality in aphids: opportunities and directions. J Chem Ecol. https://doi.org/ 10.1007/s10886-018-0955-Z

Amsalem E, Orlova M, Grozinger CM (2015) A conserved class of queen pheromones? Re-evaluating the evidence in bumblebees (Bombus impatiens). Proc R Soc B 282:20151800 
Billeter J-C, Wolfner MF (2018) Chemical cues that guide female reproduction in Drosophila melanogaster. J Chem Ecol. https://doi.org/ 10.1007/s10886-018-0947-z

Bradbury J, Vehrencamp S (2001) Principles of animal communication. Sinauer associates, Inc. In: Sunderland. USA, Massachusetts

Champlin AK (1971) Suppression of oestrus in grouped mice: the effect of various densities and the possible nature of the stimulus. J Reprod Fertil 27:233-241

Coombes HA, Stockley P, Hurst JL (2018) Female chemical signaling underlying reproduction in mammals. J Chem Ecol

d'Ettorre P, Lenoir A (2010) Nestmate recognition. Ant Ecology, pp:194-209

Dani FR, Turillazzi S (2018) Chemical communication and reproduction partitioning in social wasps. J Chem Ecol. https://doi.org/10.1007/ s10886-018-0968-7

Drickamer LC (1974) Sexual maturation of female house mice: social inhibition. Dev Psychobiol 7:257-265

Green JP, Holmes AM, Davidson AJ, Paterson S, Stockley P, Beynon RJ, Hurst JL (2015) The genetic basis of kin recognition in a cooperatively breeding mammal. Curr Biol 25:2631-2641

Hamilton WD (1972) Altruism and related phenomena mainly in the social insects. Annu Rev Ecol Syst 2:193-232

Hoffmann KH, Dettner K, Tomaschko KH (2006) Chemical signals in insects and other arthropods: from molecular structure to physiological functions. Physiol Biochem Zool: Ecol Evol Approaches 79: 344-356

Holldobler B, Wilson EO (1990) The ants. Harvard University press. In: Cambridge. USA, Massachusetts

Howard RW, Blomquist GJ (2005) Ecological, behavioral, and biochemical aspects of insect hydrocarbons. Annu Rev Entomol 50:371-393

Jemiolo B, Novotny M (1993) Long-term effect of a urinary chemosignal on reproductive fitness in female mice. Biol Reprod 48:926-929

Jemiolo B, Novotny M (1994) Inhibition of sexual maturation in juvenile female and male mice by a chemosignal of female origin. Physiol Behav 55:519-522

Kather R, Martin SJ (2015) Evolution of cuticular hydrocarbons in the hymenoptera: a meta-analysis. J Chem Ecol 41:871-883

Keller L, Nonacs P (1993) The role of queen pheromone in social insects: queen control or queen signal? Anim Behav 45:787-794

Kocher SD, Grozinger CM (2011) Cooperation, conflict, and the evolution of queen pheromones. J Chem Ecol 37:1263-1275

Korb J (2018) Chemical fertility signaling in termites: idiosyncrasies and commonalities in comparison with ants. J Chem Ecol. https://doi. org/10.1007/s10886-018-0952-2

Le Conte Y, Hefetz A (2008) Primer pheromones in social hymenoptera. Annu Review Entom 53:523-542

Lhomme P, Hines HM (2018) Reproductive dominance strategies in insect social parasites. J Chem Ecol. https://doi.org/10.1007/s10886018-0971-z
Massey A, Vandenbergh JG (1980) Puberty delay by a urinary cue from female house mice in feral populations. Science 209:821

McIntosh TK, Drickamer LC (1977) Excreted urine, bladder urine, and the delay of sexual maturation in female house mice. Anim Behav 25:999-1004

Michener CD (1974) The social behavior of the bees. Harvard University press. In: Cambridge. USA, Massachusetts

Nodari F, Hsu FF, Fu X, Holekamp TF, Kao LF, Turk J, Holy TE (2008) Sulfated steroids as natural ligands of mouse pheromone-sensing neurons. J Neurosci 28:6407

Nunes TM, Oldroyd BP, Elias LG, Mateus S, Turatti IC, Lopes NP (2017) Evolution of queen cuticular hydrocarbons and worker reproduction in stingless bees. Nat Ecol Evol 1:0185

Oi CA, Millar JG, van Zweden JS, Wenseleers T (2016) Conservation of queen pheromones across two species of vespine wasps. J Chem Ecol 42:1175-1180

Schulz S, ed (2004) The chemistry of pheromones and other semiochemicals i: topics in current chemistry. vol 239. Springer, New York, USA

Smith AA, Liebig J (2017) The evolution of cuticular fertility signals in eusocial insects. Curr Opinion Insect Sci 22:79-84

Steiger S, Stökl J (2018) Pheromones regulating reproduction in burying beetles and an outlook on other social beetles. J Chem Ecol. https:// doi.org/10.1007/s10886-018-0982-9

Steitz I, Kingwell C, Paxton R, Ayasse M (2018) Evolution of castespecific chemical profiles in halictid bees. J Chem Ecol

Stökl J, Steiger S (2017) Evolutionary origin of insect pheromones. Curr Opinion Insect Sci 24:36-42

Symonds MRE, Elgar MA (2008) The evolution of pheromone diversity. Trends Ecol Evol 23:220-228

Van Der Lee S, Boot LM (1955) Spontaneous pseudopregnancy in mice. Acta Physiol Pharmacol Neerl 4:442-444

Van Oystaeyen A et al. (2014) Conserved class of queen pheromones stops social insect workers from reproducing. Science 343:287-290

Villalta I, Abril S, Cerdá X, Boulay R (2018) Queen control or queen signal in ants: what remains of the controversy 25 years after Keller and nonacs' seminal paper? J Chem Ecol. https://doi.org/10.1007/ s10886-018-0974-9

Wilson EO, Holldobler B (2005) Eusociality: origin and consequences. Proc Natl Acad Sci U S A 102:13367-13371

Wyatt TD (2014a) Introduction to chemical signaling in vertebrates and invertebrates. Neurobiology of chemical communication. In: CRC press/Taylor \& Francis. USA, Boca Raton

Wyatt TD (2014b) Pheromones and animal behavior: Chemical signals and signatures. Cambridge. Cambridge Univ. Press. JOCED-18-00182 